\title{
Evaluation of Urban Public Transport: A Case Study of Yarmouk University
}

\author{
Ahmad H. Alomari ${ }^{1 *}$, Malek H. Aldalal'ah ${ }^{2}$, Majd Al-Deen M. Al-Dalaika ${ }^{3}$, Ghaida K. Sawae ${ }^{4}$, Shaima K. Sawae ${ }^{5}$, and \\ Doa'a M. Al-Alawneh ${ }^{6}$
}

Assistant Professor of Civil Engineering, Yarmouk University (YU) P.O. Box 566 - Irbid 21163, Jordan

DOI: $10.36348 /$ sjce.2021.v05i01.002

| Received: 29.01.2021 | Accepted: 16.02.2021 | Published: 17.02.2021

*Corresponding author: Ahmad H. Alomari

\section{Abstract}

Universities with urban campuses are often seeking solutions to congestion and parking problems in their neighborhoods. Yarmouk University (YU), Irbid-Jordan, faces severe pressure from the continuous and dynamic activities with high traffic congestion due to its location. This paper surveyed the significant characteristics of commuters to the YU campus and explored the quality and efficiency of existing offered public transport services. A sample of nearly 1006 students, faculty, and staff at the campus was surveyed using an online, paper, and one to one questionnaire surveys. Results showed that majority of travelers (39.8\%) to campus were from Qasabet Irbid (Irbid central area). Also, $41 \%$ reported that total journey time needed to campus was between thirty minutes to one hour. It is also found that a substantial proportion of respondents $(68.6 \%)$ do not own a passenger car. The most common parking problems mentioned by respondents who commute to campus were the insufficient parking spaces $(30.3 \%)$, not covered parking (20.5\%), and walking long distances from parking lots to their destination (19.9\%). Furthermore, 52\% of the respondents reported using public transport daily, $45.8 \%$ stated arriving at the campus in the early morning (5AM-8:30AM), $49.2 \%$ stated leaving the campus in the early afternoon (Noon-3:00PM), 36\% stated that Sunday was the hardest day to get to university, and $30.3 \%$ stated that it was Thursday. This research value arises from the anticipated analysis that may help understand campus community travelers' behavior to enhance future planning efforts in different urban universities according to the existing situation.

Keywords: Public Transport, University, Campus, Transit, Urban, Community.

Copyright () 2020 The Author(s): This is an open-access article distributed under the terms of the Creative Commons Attribution 4.0 International License (CC BY-NC 4.0) which permits unrestricted use, distribution, and reproduction in any medium for non-commercial use provided the original author and source are credited.

\section{INTRODUCTION}

Universities are among the most attractive areas for various trip types in urban areas during different seasons around the year. They are a major center for many students, teachers, workers, visitors locally and internationally, and the various shops and restaurants surrounding the campus area. The causes of congestion vary around universities in urban areas, and an essential part of these reasons is the levels of service offered by public transport and its reliability. One of the most important goals of public transportation is to reduce the dependency on private vehicles by switching the use to public modes of transport and decrease the need for parking spaces, whether on-street or off-street parking.
Any evaluation conducted for the mode choices in urban areas, it is realistic to focus further on the university campus within, and its users travel behavior; whether they are students, faculty, or staff since they represent a significant proportion of any urban regions' commuters [1]. Since universities are considered large attractors and generators of traffic, it is essential to effectively attain stability between the pros and cons of these institutions' urban location [2]. Furthermore, available land in urban campuses is constrained. So, adding more parking spaces are usually restricted except on the periphery of the campus. However, students, faculty, and staff are competing more acutely for limited available parking spaces. The role of transit in supplying access to campuses has increased and provided more challenges to both universities' administrators and transit providers to enhance mobility and accessibility. 
An overall literature review was conducted in this paper to analyze the research being done on evaluating the mode choices of universities' commuters and how university campuses improved a partnership with public transport to achieve the modal shift among their students and staff. Many frameworks exist to support transit agencies to operate and monitor their performance on urban campuses.

\section{Analyzing University Commuters' Mode Choices to Campus}

Researchers have investigated university commuters' attitudes towards auto use and the factors that would encourage them to carpool and take transit to campus. To achieve this, surveys were performed in several ways, such as self-reported questionnaires using the internet or field interviews. Akar et al. [3] inspected the campus community's travel patterns at Ohio State University as a large campus setting. Random samples of 3,317, including faculty, staff, and student, were surveyed using a web-based questionnaire. Results showed that proximity to bus stops and bicycle lanes increases the tendency of choosing these modes of travel. However, students are more likely to travel by alternative modes than are faculty and staff members. While individuals who are worried about travel time, safety, the flexibility of departure time, and the ability to stop on the way to/from campus are more likely to drive alone to campus.

Rotaris \& Danielis [2] analyzed mode choice decisions made by the teaching and administrative staff and by the students at the University of Trieste, Italy. They interviewed a sample of 372 consisted of $56 \%$ women and $44 \%$ men of different ages. Students are $71 \%$ of the sample, the teaching staff is $8 \%$, and $21 \%$ is the administrative staff. They found that changing parking regulations and fully subsidizing the bus services will significantly affect mode choice in favor of bus use, especially for teaching and administrative staff. While the student's mode choice would be impacted only if an hourly parking tariff is introduced.

Barla, Lapierre, Daziano, \& Herrmann [4] interviewed 705 students and employees at the University of Laval, Canada. Moreover, they estimated the reduction in automobile modal share under different scenarios. The results revealed that a policy mix of public transport subsidization, increased public transport speed, and parking pricing would reduce the use of private vehicles by $80 \%$. Another two studies, based on stated preference data collected from students and employees in the University of Eindhoven, Netherlands [5], and the University of Los Angeles, United States [6], exposed that availability of a discounted transit pass, and long-term on-campus parking permit is an effective and politically acceptable policy to reduce automobile ridership in favor of public transport.
Zhou et al. [7] surveyed 1661 students online to investigate the control factors of the students' mode choice at Iowa State University, United States. Results showed that students at this urban campus tend to use "non-driving-alone" modes such as buses, biking, and walking.

\section{Supporting Transit Agencies Cooperation with University Campuses}

Concerns about greenhouse gas emissions and the role of the automobile as a primary contributor to greenhouse gas emissions have introduced a renewed interest in programs endorsing commute alternatives. Several studies investigated universities and transit agencies frameworks and cooperative efforts to achieve a modal shift among the population of university campuses.

Brown, Baldwin Hess, \& Shoup [8] investigated providing fare-free public transit at the University of California, Los Angeles, United States. Unlimited access or fare-free transit service for all students, as well as faculty and staff on some campuses, is not free transit, but it is an alternative way to pay for it. The university pays the transit agency for the rides taken by the members of the campus community. The findings showed that during the first year of Unlimited Access, bus ridership for traveling to campus increased by 56 percent, while automobile ridership decreased by 20 percent. Sandidge [9] identifies how universities can encourage transit ridership by reviewing five universities in the United States cooperating with transit providers. They found that the partnership between these two entities by developing incentives for transit pass programs is significantly beneficial for decreasing automobile traffic on campus and increasing transit ridership.

Beyond this, urban campuses present a challenge of public transport planning in a private vehicle dominated community. Luathep, Suttipan, \& Jaensirisak [10] investigated providing electric bus service for daily trips to Prince of Songkla University, in southern Thailand. Stated Preference (SP) surveys were applied to examine travelers' responses to different policies in encouraging a modal shift from private vehicles to public transport. The results illustrated that the integrated policies between improvement of bus service (waiting time and travel time reduction) and management of private vehicle parking (parking restriction and pricing) could endorse the bus system and reduce $\mathrm{CO}_{2}$ emissions in the community. Bartman, Ogle, Chowdhury, \& Dunning [11] proposed a flexible framework that integrates planning, operations, and performance measurement activities to evaluate transit in the context of overall mobility. A case study of Clemson University's oncampus transit route was examined. The findings suggested that the proposed framework can be useful for large academic institutions and urban campuses. 
Ahmad H. Alomari et al., Saudi J Civ Eng, Feb, 2021; 5(1): 8-17

The framework allows for continual feedback to achieve the optimal performance of the transit system that satisfies stakeholders' needs.

\section{Study Area and Significant of Research}

The statistics show that the total population in Jordan reached 10,544,000 inhabitants in 2019, with total registered vehicles of 1,677,061 [12, 13]. Amman population, the capital, reached 4,430,700 people, while Irbid city 1,957,000 people by the end of 2019 [12]. The city of Irbid, northern Jordan, suffers from increasing traffic congestion over time. The metropolitan area of Irbid has two major congested traffic areas; the first one is the commercial city center, coded $\mathrm{C} 1\left(32.5568^{\circ} \mathrm{N}, 35.8469^{\circ} \mathrm{E}\right)$ in Figure 1, where the shops and markets from different sectors are concentrated. The other major congested area is the surrounding network of Yarmouk University (YU),
Irbid central bus station, and several other shopping malls (coded C2 $\left[32.5378^{\circ} \mathrm{N}, 35.8553^{\circ} \mathrm{E}\right]$ in Figure 1).

The primary goal of this study was to evaluate the public transport system around YU and the community's travel patterns by:

- Interviewing a sample of students, faculty, and staff at the campus using online, paper, and one to one questionnaire surveys.

- Understanding the traffic flow characteristics and travel patterns of travelers around YU and the transportation choices on the campus.

- Draw some recommendations for YU's subjective perceptions to reduce single-occupancy vehicle travel and increase the dependency of universities' travelers on public transport.

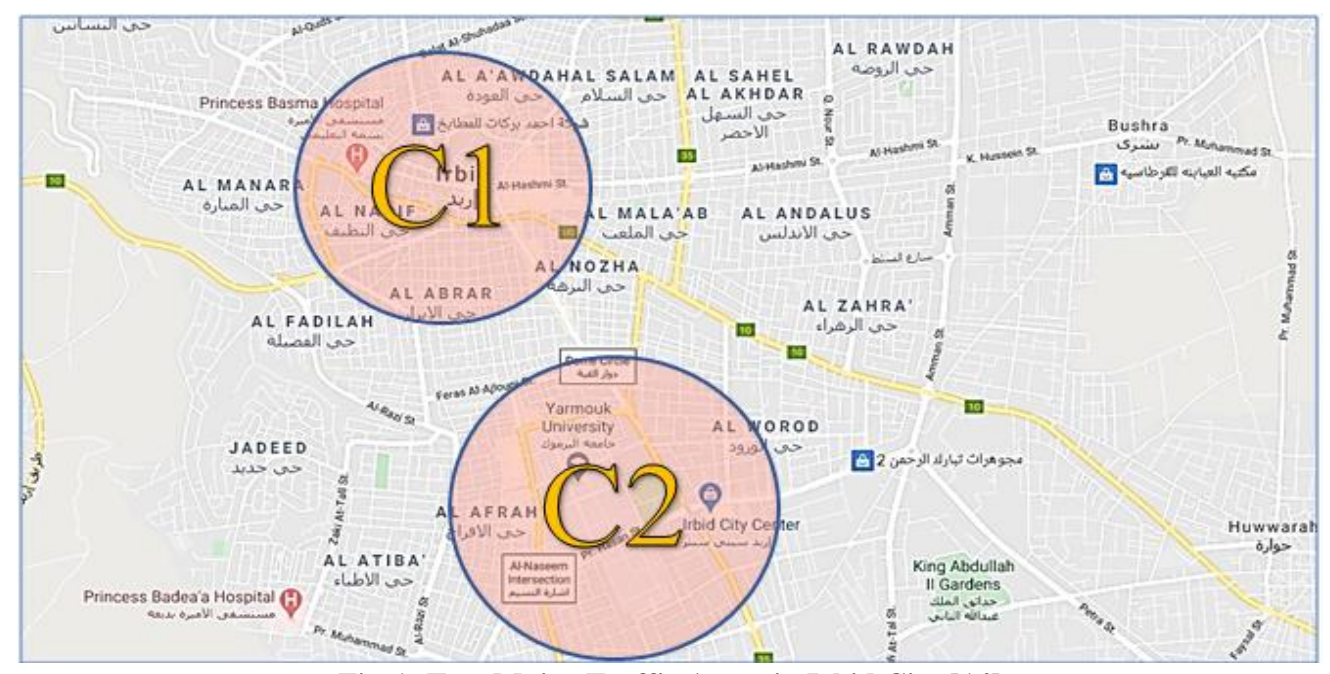

Fig-1: Two Major Traffic Areas in Irbid City [14]

As the unique characteristics of $\mathrm{YU}$ and its location in an urban area, a considerable amount of data was collected through surveys. This research value arises from the anticipated analysis that may help understand campus community travelers' behavior to enhance future planning efforts in different urban and rural universities according to the existing situation.

\section{METHODOLOGY}

This research performed a measurable analysis to examine travel behaviors among YU students, faculty, and staff members. The primary methodology for this study proceeded based on an online, paper, and one to one questionnaire surveys. The descriptive analysis was performed based on a series of logical steps to outline recommendations for subjective perceptions on an urban campus to identify campus community travelers' travel patterns.

In this study, the target population was reported from a volunteer online, paper, and one-to-one questionnaire survey invitation to all students, faculty, and staff at the YU campus. A total of 1006 random samples contributed to this survey. The purpose of the survey was to address the transportation choices of students, faculty, and staff to campus, their desire to drive alone, and their willingness to shifting modes. This survey also showed how travelers drive during the days per week, share vehicles, and search for parking. Moreover, this survey explored how different variables influenced the dependency on public transit at $\mathrm{YU}$ among students, faculty, and staff. This research performed anonymous personal information, and unidentified socio-economic characteristics of students, faculty, and staff, based on the Institutional Review Board (IRB) rules at YU. The survey structure was designed into different sets of questions. The questions reviewed several socio-demographic characteristics (SDC), including current residential address, number of people per household, travel mode, cost of travel, and passenger car availability in their households. Also, the questions evaluated how satisfied the travelers with their mode of travel to university, their daily commuting patterns with days and times, their parking habits, and parking problems they run across. 
Ahmad H. Alomari et al., Saudi J Civ Eng, Feb, 2021; 5(1): 8-17

\section{RESULTS AND DISCUSSION}

Summary statistics for the variables were evaluated using Statistical Package for the Social Sciences [16]. This study presented contingency table analysis to examine the relationships between variables of the gathered data. Results were evaluated to observe relationships within the data that might not be readily apparent when analyzing total survey responses. In this study, a random sample of 1006 respondents showed that 887 were students $(88.2 \%)$, and 119 were faculty and staff members $(11.8 \%)$, as shown in Figure 2.

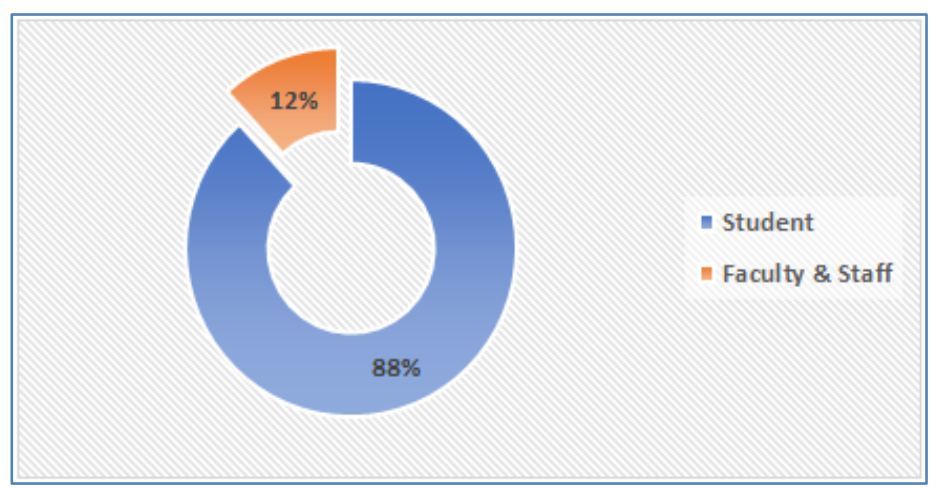

Fig-2: Distribution of Respondents

Based on the survey results with valid responses, the geographic distribution of residential location was represented by $39.8 \%$ living in Qasabet Irbid, $16.7 \%$ living outside Irbid, 9.9\% living in AlKurah, $8.9 \%$ living in Bani-Obeid, $8.1 \%$ living in Bani-
Kenanah, 5.2\% living in Al-Mazar Alshmali, 3.5\% living in Al-Ramtha, 3.3\% living in Al-Aghwar Alshmaliyah, $2.7 \%$ living in Al-Wastiyah, and 2\% living in Al-Taibeh (Figure 3).

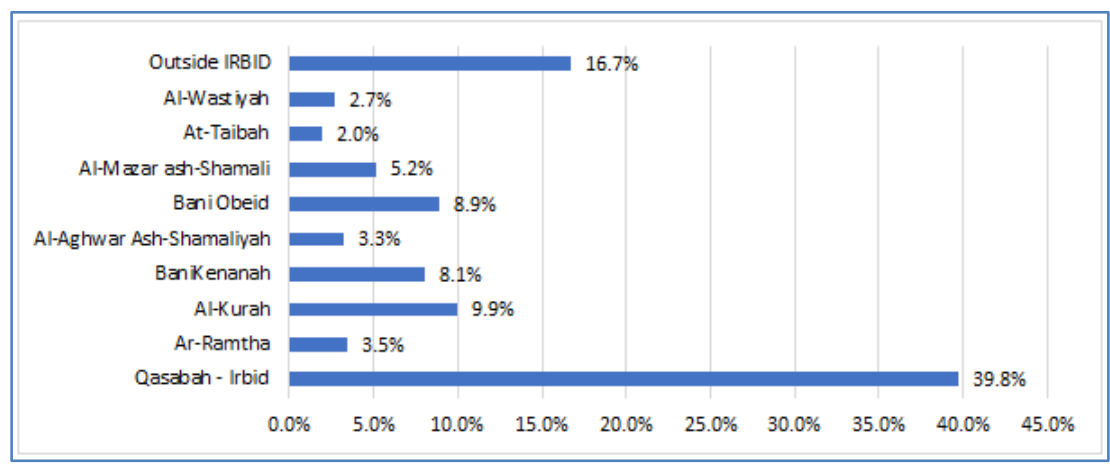

Fig-3: Geographic Distribution of Respondents

Most respondents reported living with five or more persons in their households $(83.4 \%)$, as shown in Figure 4. According to the transportation mode to campus, $66 \%$ identified transit as their predominant transportation mode $(60.8 \%$ for Buses and $5.2 \%$ for Taxis), followed by $22.9 \%$ used passenger car (PC), $1.5 \%$ used Careem/Uber, and $9.6 \%$ regularly walked to campus. Only $30.3 \%$ of them were completely satisfied with their way of traveling to YU (Figure 5).

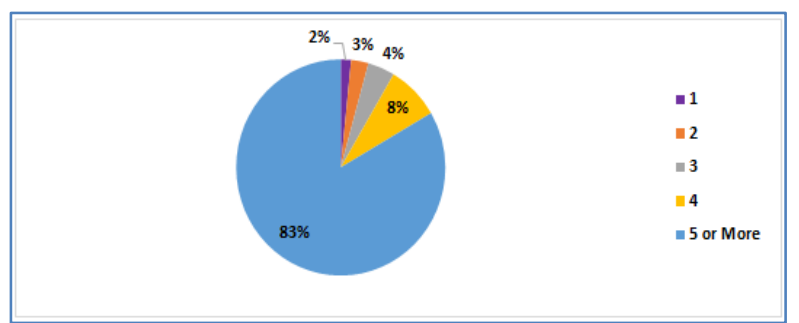

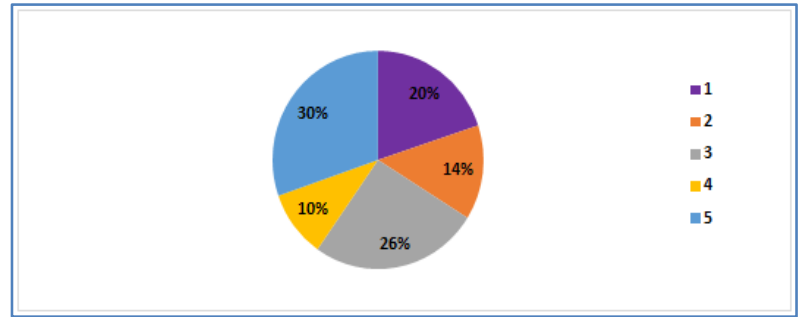

Fig-5: Satisfaction of Respondents with the way you are travel to university? (1=very satisfied $5=$ not satisfied)

A substantial proportion of respondents $(68.6 \%)$ do not own a passenger car. The other $31.4 \%$ indicated commuting to campus by their own cars, $55.1 \%$ of them stated having only one vehicle available for private use and $32 \%$ having two vehicles in their households (Figure 6).

Fig-4: Average Person Lives in a Household 
Ahmad H. Alomari et al., Saudi J Civ Eng, Feb, 2021; 5(1): 8-17

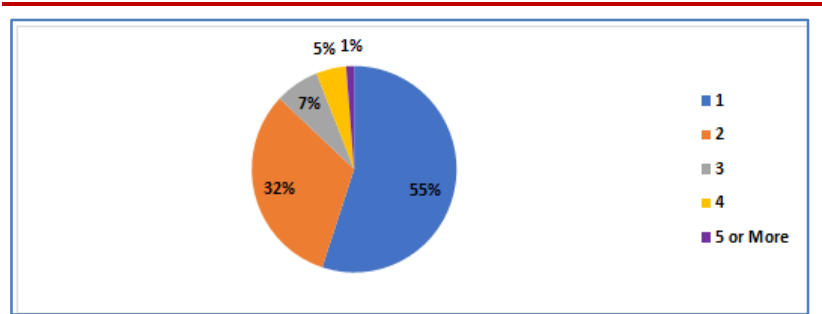

Fig-6: Average Number of Cars per Household for Private Use.
As shown in Figure 7, respondents who commute to campus specified the parking problems consequently; not enough parking spaces (30.3\%), not covered parking $(20.5 \%)$, walking a long distance from parking lots to their destination (19.9\%), the impossibility of leaving the parking lot during the day and finding a parking space when getting back (5.3\%), problems of safety after dark $(3.3 \%)$, and problems of safety in terms of incidents (1\%). Only $12 \%$ reported not having any parking problems.

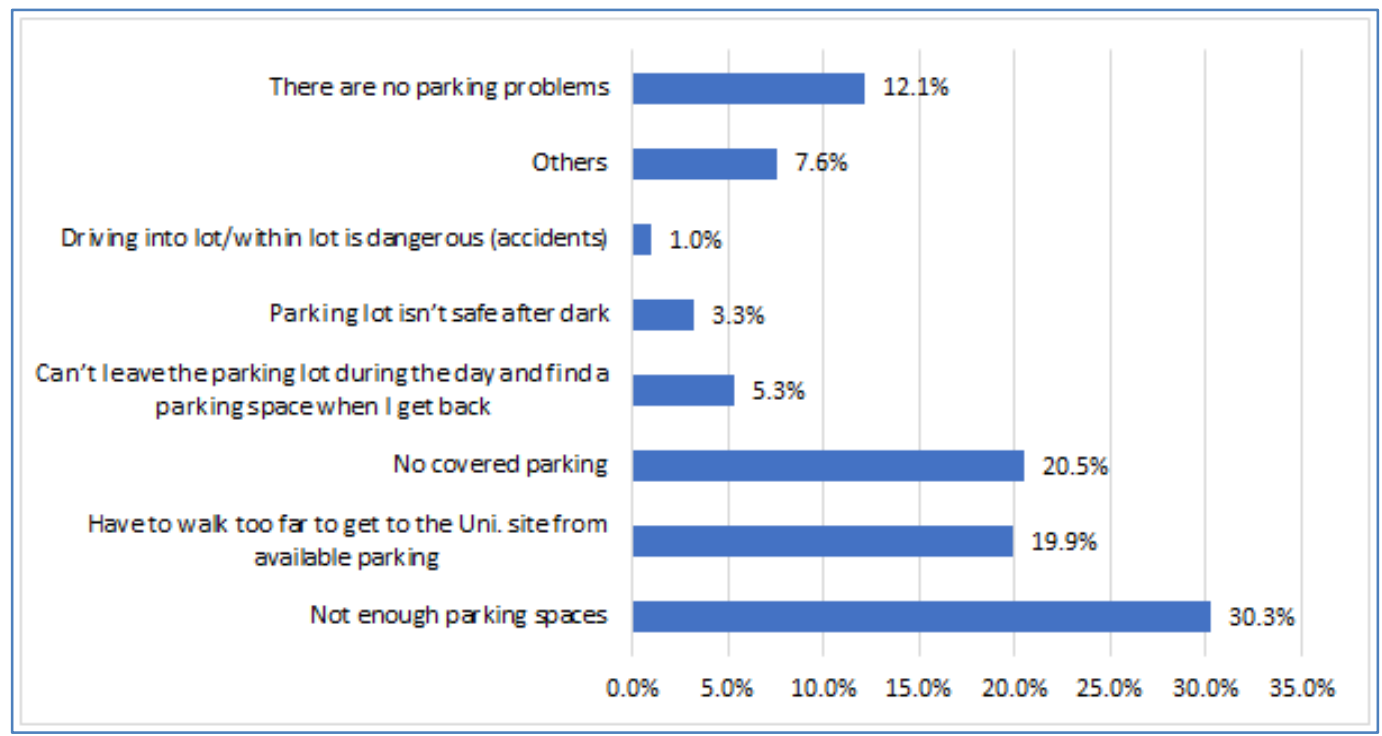

Fig-7: Average Number of Cars per Household for Private Use

This survey revealed that despite a considerable proportion of respondents who do not own a PC (68.6\%), approximately half of these students $(49.6 \%)$ are not driving to campus because they cannot afford a car $(36.1 \%)$ or the costs of gas and insurance (13.5\%), 25.3\% do not have a driver's license, $11.2 \%$ do not need to use a car, and only $1.6 \%$ cannot drive due to some medical/physical conditions (Figure 8).

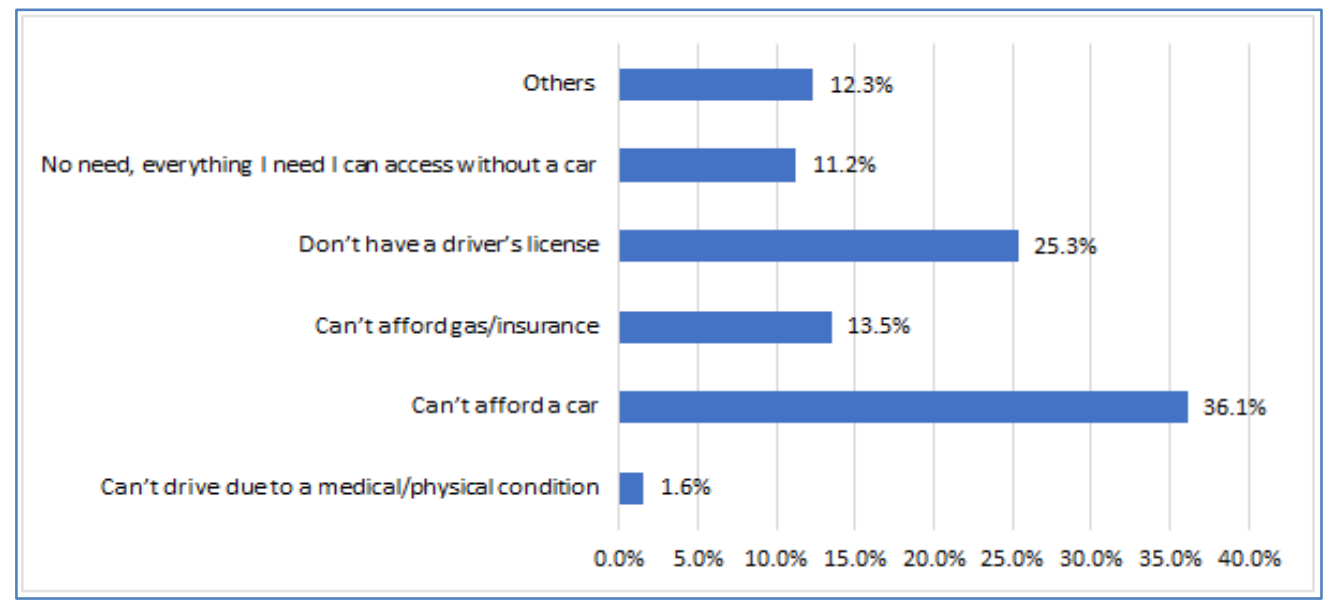

Fig-8: Reasons for not owning a Car

A significant percentage of respondents $(57.3 \%)$ who used buses to campus stated that they normally take two different buses to reach their destination; likewise, $30 \%$ take only one bus, $8.7 \%$ take three buses, $2.4 \%$ take four buses, and $1.5 \%$ take five or more buses, as shown in Figure 9. Roughly, $40.5 \%$ of respondents reported their travel cost of approximately 1-1.99 JODs per day when traveling to campus (Figure $10)$. 
Ahmad H. Alomari et al., Saudi J Civ Eng, Feb, 2021; 5(1): 8-17

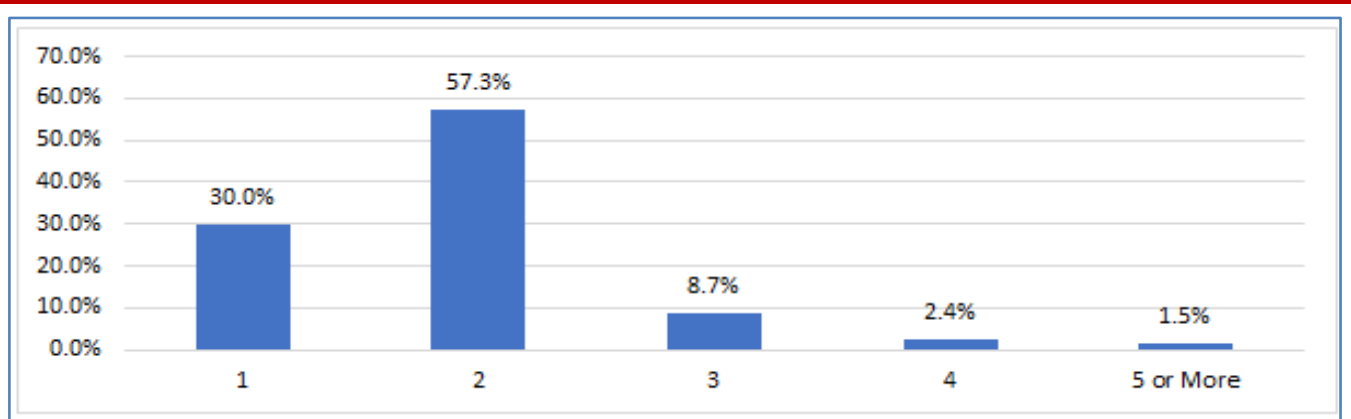

Fig-9: Number of Buses Used to Reach the University

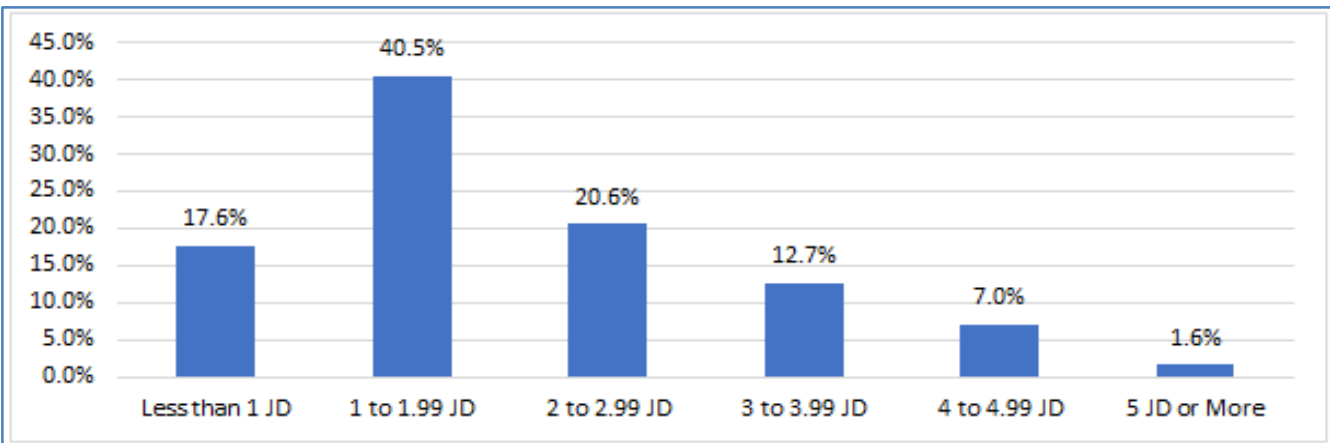

Fig-10: Cost to go Back and Forth to University Each Day (Gas, Parking, and Tolls)

In this study, around $41 \%$ reported that the total journey time needed to university campus was between thirty minutes to one hour. As well, $33.2 \%$ needed less than thirty minutes, $21.6 \%$ needed one to two hours, $2.9 \%$ needed two to three hours, and $1.4 \%$ needed more than three hours, as shown in Figure 11.

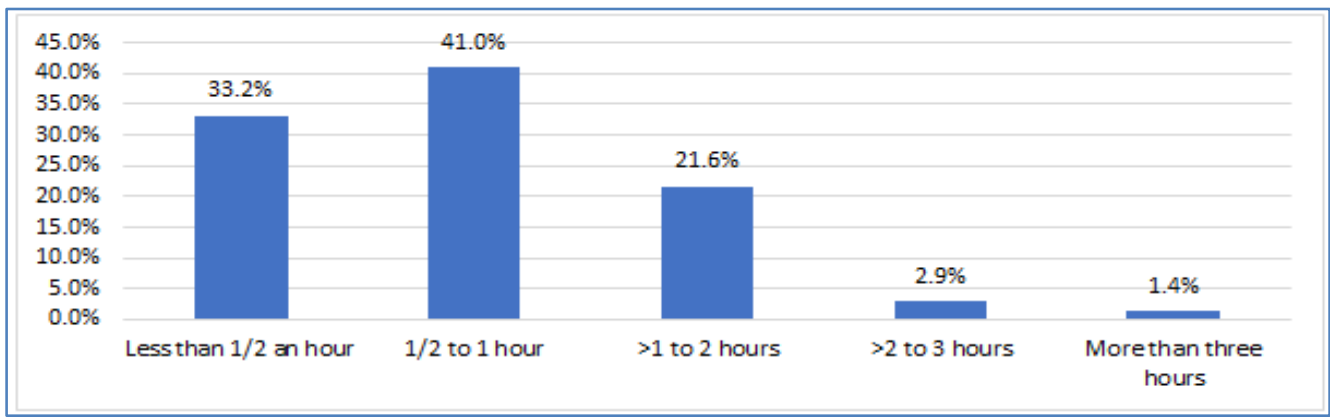

Fig-11: Cost to go back and forth to University each day (gas, parking, tolls)

As seen in Figure 12, around $32.4 \%$ of respondents reported that the time needed to walk from their home to the nearest public transport stop was less than five minutes, $29.2 \%$ needed five to ten minutes,
$20.6 \%$ needed ten to fifteen minutes, $10 \%$ needed fifteen to thirty minutes, and $7.7 \%$ needed thirty minutes to one hour.

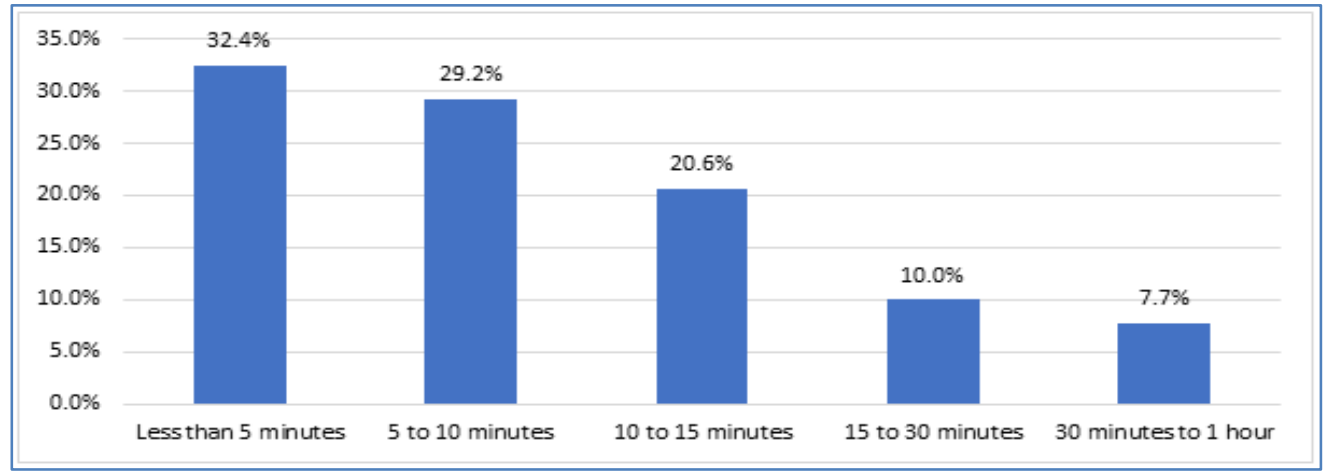

Fig-12: Walking Time from Home to the Nearest Public Transport Stop 
Ahmad H. Alomari et al., Saudi J Civ Eng, Feb, 2021; 5(1): 8-17

Moreover, approximately half of the respondents $(52 \%)$ reported using public transport daily, while $16.5 \%$ were using transit weekly, $12.2 \%$ rarely, $9 \%$ occasionally, 3.5\% monthly. Around $6.8 \%$ of the respondents reported never using public transport to campus, as shown in Figure 13.

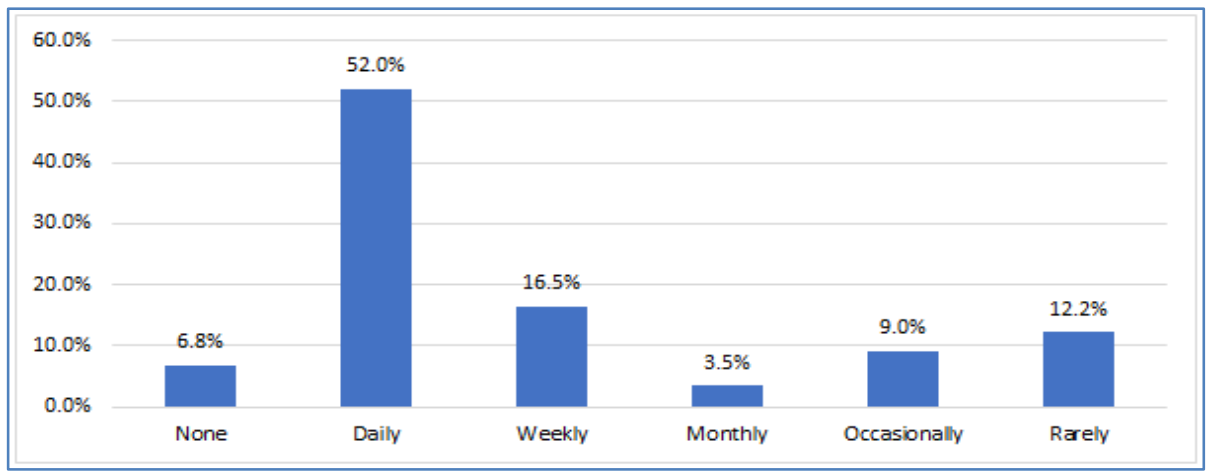

Fig-13: Walking Time from Home to the Nearest Public Transport Stop

On one hand, about $45.8 \%$ of respondents stated arriving at the campus in the early morning ( 5 $\mathrm{AM}-8: 30 \mathrm{AM})$, and $41.5 \%$ were arriving in the late Morning (8:30 AM - Noon), as shown in Figure 14. On the other hand, $49.2 \%$ stated leaving the campus in the early afternoon (Noon - 3:00 PM), and 39.7\% were leaving in the late afternoon (3:00 PM - 6:00 PM), as shown in Figure 15. The highest percentage of respondents $(44.5 \%)$ reported that in the early afternoon (Noon - 3:00 PM) was the hardest time to get to and from the university (Figure 16). Correspondingly, 36\% stated that Sunday was the hardest day to get to university, and $30.3 \%$ stated that it was Thursday (Figure 17).

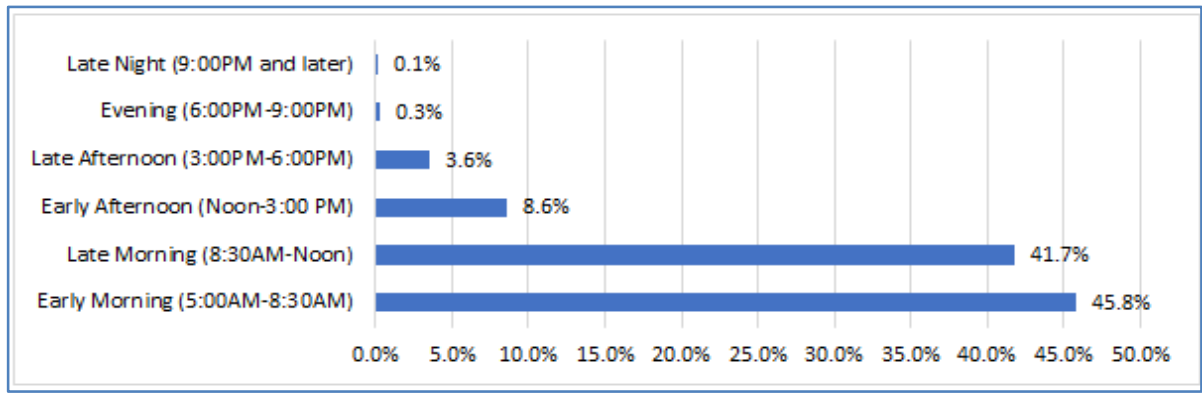

Fig-14: Arrival Distribution to Campus during the Day

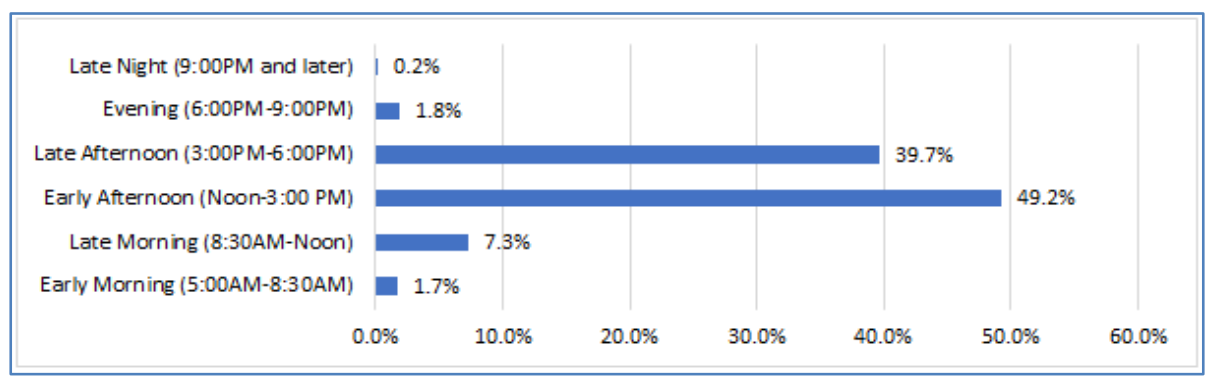

Fig-15: Departing Distribution from Campus during the Day

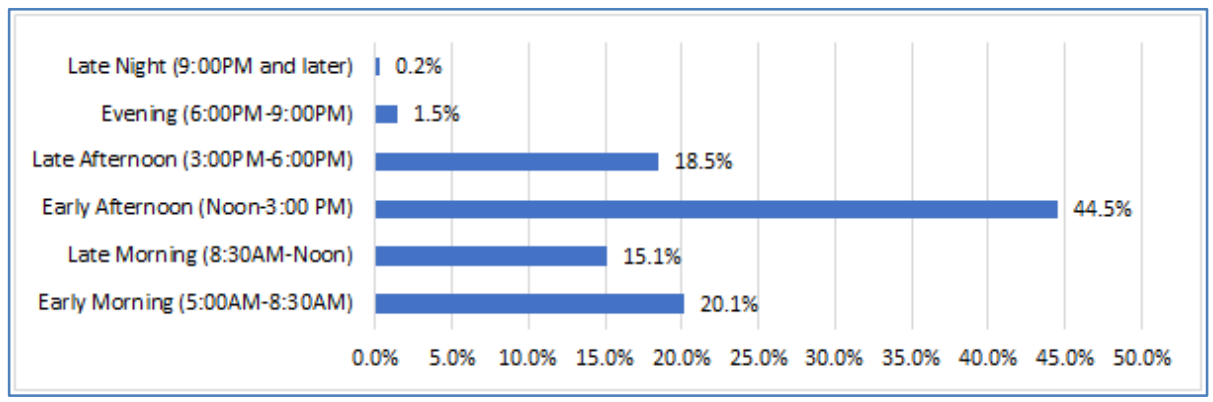

Fig-16: The Hardest Time(s) of the Day to Get to and from University. 


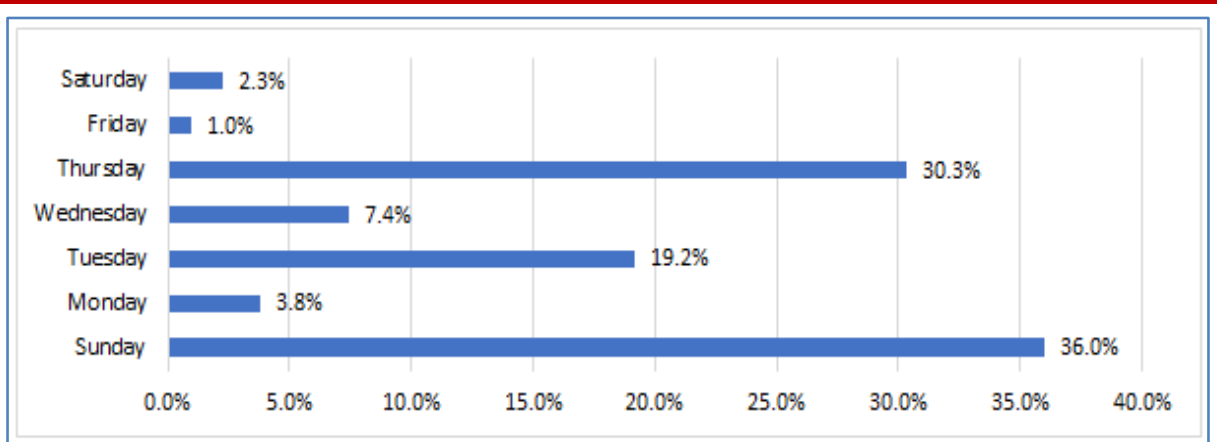

Fig-17: The Hardest Day(s) of the Week to Get to and from University

Participants in this survey were asked whether they make stops on their way to campus and the reasons for trip chaining. Almost $10 \%$ reported stopping for eating or picking up a carpooler, as shown in Figure 18. They were asked to mention the reasons for trip chaining in their way out of campus to their homes. Around $15.9 \%$ reported stopping for eating, $13.6 \%$ for shopping, and $7.1 \%$ for picking up a carpooler, as shown in Figure 19.

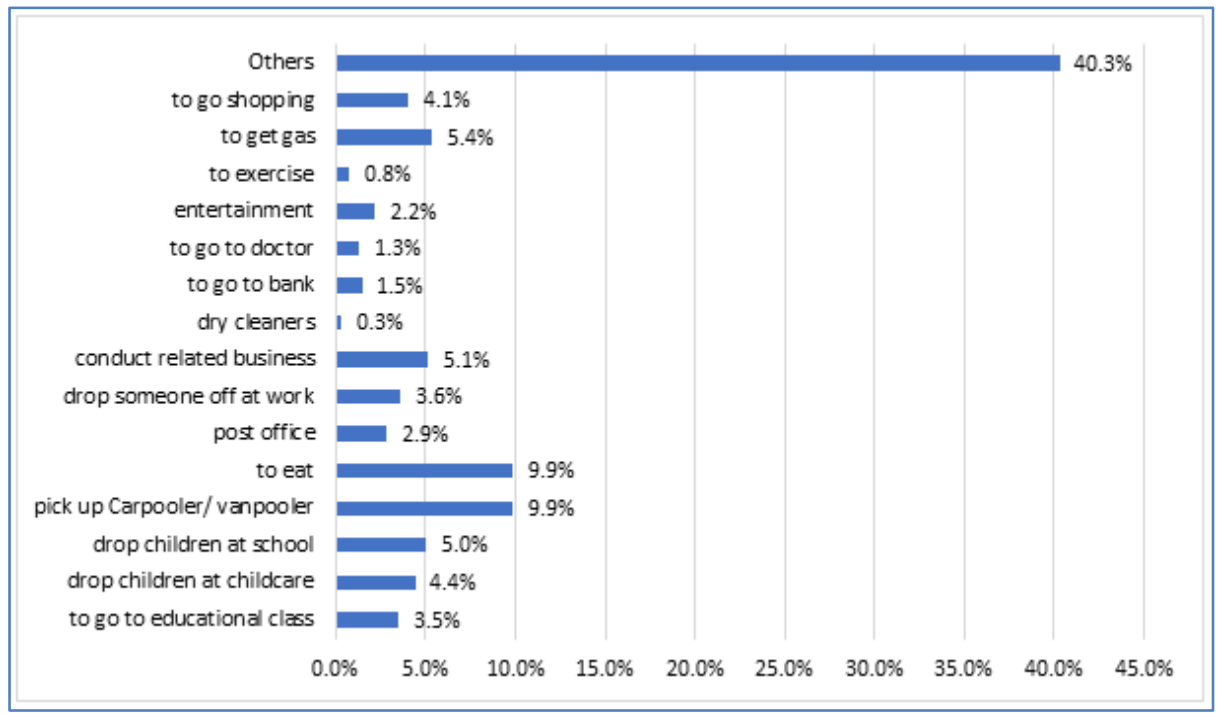

Fig-18: Reasons for Stopping on the Way to Campus

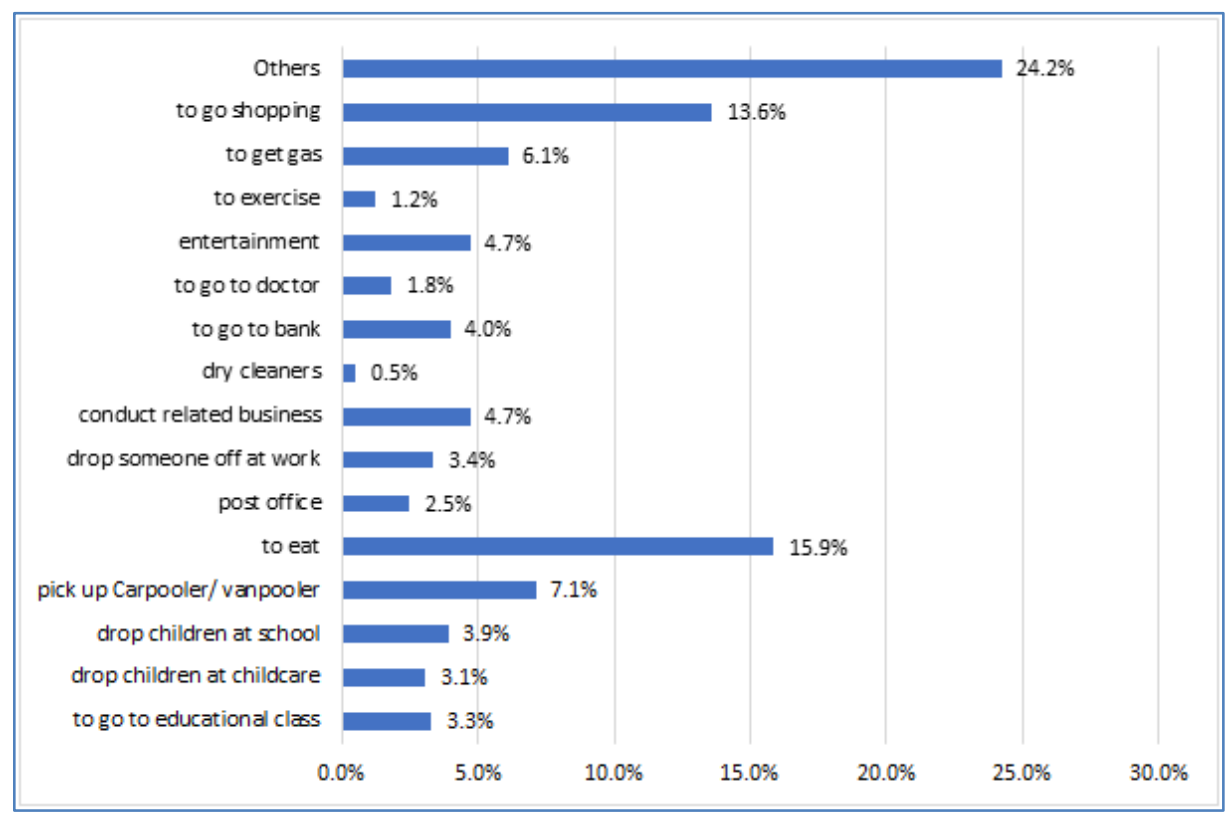

Fig-19: Reasons for Stopping on the Way out of Campus 
Ahmad H. Alomari et al., Saudi J Civ Eng, Feb, 2021; 5(1): 8-17

\section{CONCLUSIONS \& RECOMMENDATIONS}

The existence of a university campus in an urban area is considered a massive trip generator that can cause a significant increase in the number of trips (demand) in the traffic network around. The location of any campus is a substantial element in its planning, design, and supplying of several services to the users. This study assessed the public transport system around YU and the community's travel patterns through interviewing a 1006 sample of students, faculty, and staff at the campus using online, paper, and one to one questionnaire surveys. Understanding the traffic flow characteristics and travel patterns of travelers to/from YU and the transportation choices on-campus can help draw some recommendations for YU's subjective perceptions to reduce single-occupancy vehicle travel and increase the dependency of universities' travelers on public transport.

Based on the survey results, the primary supplier of travelers came from Qasabet Irbid with a percentage of $39.8 \%$, and then followed by travelers from outside Irbid with a percentage of $16.7 \%$. Around $41 \%$ reported that the total journey time needed to university campus was between thirty minutes to one hour. As well, 33.2\% needed less than thirty minutes, and $21.6 \%$ needed one to two hours. Most respondents reported living with five or more persons in their households $(83.4 \%)$. According to the transportation mode to campus, $66 \%$ identified transit as their predominant transportation mode $(60.8 \%$ for Buses and $5.2 \%$ for Taxis), followed by $22.9 \%$ used passenger car (PC), $1.5 \%$ used Careem/Uber, and $9.6 \%$ regularly walked to campus. Only $30.3 \%$ of them were completely satisfied with their way of traveling to YU campus. A substantial proportion of respondents $(68.6 \%)$ do not own a passenger car, and the other $31.4 \%$ indicated commuting to campus by their cars. The most common parking problems mentioned by respondents who commute to campus were the insufficient parking spaces $(30.3 \%)$, not covered parking $(20.5 \%)$, and walking a long distance from parking lots to their destination (19.9\%). Only $12 \%$ reported not having any parking problems. Moreover, a significant percentage of respondents who used buses to campus stated that they usually take two different buses to reach their destination $(57.3 \%)$. Furthermore, approximately half of the respondents $(52 \%)$ reported using public transport daily. With regards to the trip's peak-times during the day and among the week, about $45.8 \%$ of respondents stated arriving at the campus in the Early Morning (5 AM - 8:30 AM), and 41.5\% were arriving in the late Morning (8:30 AM-Noon). Conversely, $49.2 \%$ stated leaving the campus in the early afternoon (Noon - 3:00 PM), and 39.7\% were leaving in the late afternoon (3:00 PM - 6:00 PM). Correspondingly, $36 \%$ stated that Sunday was the hardest day to get to university, and $30.3 \%$ stated that it was Thursday. Finally, around $10 \%$ reported stopping on their way to campus to eat or pick up a carpooler. In contrast, around $15.9 \%$ reported stopping on their way out of campus to their homes for eating, $13.6 \%$ for shopping, and $7.1 \%$ for picking up a carpooler.

Based on the data collection, analysis, results, and comparisons made in this study, it is recommended to increasing the use of public transport among university students, faculty, and staff by enhancing the quality of service provided such as transit timetable for all trips serviced during the day and along the week. Also, it is recommended to enhance and maintain the infrastructure of public transport facilities such as bus stops, types of buses used, and electronic signboards. Moreover, low-fare and fare-free public transport services can create shifts toward this mode of transport from other alternative modes. It is suggested to enhance the efficiency of existing parking spaces on and around campus. This can be improved by renovating the pavement marking and signing, which can instruct the users how and where to park and the pedestrian facilities that tell them where they should move. Finally, a long-term on-campus parking permit is an effective and politically acceptable policy to reduce automobile ridership in favor of public transport. Future work will consider collecting similar data from different urban and rural campuses to explore the similarities and variations and their causes.

\section{REFERENCES}

1. Khattak, A., Wang, X., Son, S., \& Agnello, P. (2011). Travel by university students in Virginia: Is this travel different from travel by the general population?. Transportation Research Record, 2255(1), 137-145.

2. Rotaris, L., \& Danielis, R. (2014). The impact of transportation demand management policies on commuting to college facilities: A case study at the University of Trieste, Italy. Transportation Research Part A: Policy and Practice, 67, 127-140.

3. Akar, G., Flynn, C., \& Namgung, M. (2012). Understanding Travel Choices and Links to TDM: A Case study of The Ohio State University. In Proceedings of the 91st Annual Meeting of the Transportation Research Board. Washington, D.C.

4. Barla, P., Lapierre, N., Daziano, R. A., \& Herrmann, M. (2012). Reducing Automobile Dependency on Campus: Evaluating the Impact TDM Using Stated Preferences. Cahier de recherche/Working Paper, 3.

5. Van der Waerden, P., Borgers, A., \& Timmermans, H. (2006). Attitude and behavioral responses to parking measures. European Journal of Transport and Infrastructure Research, 6(4), 301-312.

6. Zhou, J. (2012). Sustainable commute in a cardominant city: Factors affecting alternative mode choices among university students. Transportation research part A: policy and practice, 46(7), 10131029. 
7. Zhou, J., Wang, Y., \& Wu, J. (2018). Mode choice of commuter students in a college town: an exploratory study from the United States. Sustainability, 10(9), 3316.

8. Brown, J., Baldwin Hess, D., \& Shoup, D. (2003). Fare-Free Public Transit at Universities: An Evaluation. Journal of Planning Education and Research, 23(1), 69-82.

9. Sandidge, S. M. (2011). Achieving Sustainability Goals Through University-Transit Partnerships. TRB Annual Meeting, No. 11-4213.

10. Luathep, P., Suttipan, S., \& Jaensirisak, S. (2015). Challenge of Public Transport Planning in Private Vehicle Dominated Community. Journal of the Eastern Asia Society for Transportation Studies, 11, 1122-1139.

11. Bartman, K., Ogle, J., Chowdhury, M., \& Dunning, A. (2011). Transit System Evaluation
Process: From Planning to Realization. ITE Journal.

12. DOS, Department of Statistics, Jordan. (2020). Estimate Number Of The Population of The Kingdom by,Locality, Sex\&families Size, and households for the end of 2019. Retrieved from http://dosweb.dos.gov.jo/DataBank/Population_Es timares/PopulationEstimatesbyLocality.pdf Accessed June, 2020.

13. PSD, Jordan Public Security Directorate. (2020). Traffic Report 2020. Retrieved from https://www.psd.gov.jo/images/docs/TrafficRep20 19.pdf Accessed June, 2020.

14. Google Maps. (2020). Retrieved from https://www.google.com/maps Accessed June, 2020.

15. IBM SPSS Software. (2020). Version 25. https://www.ibm.com/analytics/spss-statisticssoftware Accessed July 30, 2020. 